\title{
Maintenance of normal intestinal mucosa: function, structure, and adaptation
}

\author{
J A Jankowski, R A Goodlad, N A Wright
}

\begin{abstract}
Diet is of fundamental importance in the healthy functioning of alimentary epithelium, or during the disease process. Specifically, the incidence of 'nonhereditary' gastrointestinal disease varies widely throughout the world, partly because of different cultural and dietary habits. The aim of this review is to outline the mechanisms that modulate normal mucosal development and growth in the small and large intestine. In addition a brief mention will be made of morphological changes in certain pathological conditions.
\end{abstract}

(Gut 1994; supplement 1: S1-S4)

There is much evidence linking diet and maintenance of intestinal mucosal integrity. Epidemiological data have, for example, shown an association between Baker's yeast ingestion and incidence of Crohn's disease in the small bowel and the inverse relation of fibre consumption and cancer in the large bowel. ${ }^{1}$ More direct evidence of cause and effect has been forthcoming from the study of the cell biology and morphological characteristics of normal and abnormal specimens in vivo. $^{2}$

Under normal circumstances new cells of the intestine spend the first days of their lives in the cell division. Subsequently, cells become mature and acquire various specialised functions associated with digestion and protection. Although, a certain proportion of cells will undergo programmed cell death (apoptosis) or stochastic - that is, random - cell death as a result of necrosis or cell damage, most cells are lost by exfoliation into the lumen. The combination of these processes of maturation and exfoliation result in the generation of an organised morphological structure. ${ }^{2}$ The alimentary mucosa has considerable powers of adaptation some of which are physiological and can give rise to specific morphological appearances. Some means of adaptation are inflammation (localisation of excess neutrophils and lymphocytes), restitution (repair of superficial breaches of mucosal integrity by cell migration), hypertrophy (increase in cell number or size) and atrophy.

In abnormal states the mucosa must also be able to repair mucosal integrity, which include the reversible ulcer associated cell lineage, metaplasia (irreversible constitutive change of phenotype), dysplasia (abnormal differentiated phenotype), and neoplasia (abnormal cell number and abnormal differentiated phenotype). ${ }^{3}$

\section{Functions}

The two main functions of the gastrointestinal mucosa are concerned with digestion and absorption of dietary nutrients and as a defence against many noxious dietary substances and bacteria.

The digestive mechanisms of the gut reside at two levels. Luminal digestive enzymes secreted by the pancreas reduce macromolecular starch and protein to oligomeric forms (di and oligosaccharides, dipeptides to hexapeptides, free amino acids, etc), which can undergo subsequent hydrolysis to monomers by a considerable number of hydrolases of the enterocyte brush border. In addition, $\mathrm{Na}^{+} / \mathrm{K}^{+}$and ATPase pumps situated in the basolateral membrane of the enterocyte regulate salt and water balance in the enterocyte and the overall process of salt and water absorption.

Mucosal defences consist of non-specific barrier mechanisms and specific immunological responses. The first include production of copious amounts of viscous mucin (3 $1 /$ day), there is also production of an alkaline $\mathrm{pH}$ environment beneath the mucin layer by active mechanisms, saliva, which acts as a buffer and lubricant, maintenance of tight cell-cell junctions (impermeable to bacteria and large molecules), and rapid mucosal turnover quickens adaptive responses and prevents bacterial translocation.

Granulocytes, macrophages, and Paneth cells act as intramucosal phagosomes, which non-selectively, recycle medium sized intracellular particles.

More specific immunological responses include the expression of IgA immunoglobulins on the apical luminal surfaces and sensitised lymphocytes on Peyer's patches or in $T$ cell populations in intramucosal epithelium (mucosa associated lymphoid tissue that is $25 \%$ of mucosal cell mass). This last response can recognise very small epitopes (3 aminoacids).

Structure: topographical organisation of intestinal epithelia - current theory (Table I)

Recent theory suggests that the single most important intestinal cells are the stem cells. These may consist of a hierarchy of functional cells, which have a decreasing capacity to produce a large family of descendants within their own natural environment, throughout the lifetime of the adult. \\ W 12 OHS. \\ Imperial Cancer \\ Research Fund, Ro \\ R A Goodlad \\ Gastrointestinal Unit, \\ of Medicine, Guy's \\ Hospital, London
}


TABLE I Topographical organisation of the human gastrointestinal tract

\begin{tabular}{|c|c|c|c|c|}
\hline & Oesophageal epithelium & Gastric mucosa & Intestinal mucosa & Colonic mucosa \\
\hline Epithelium & Squamous & Mucus secreting & Mucus secreting & Mucus secreting \\
\hline $\begin{array}{l}\text { Proliferative com- } \\
\text { partment }\end{array}$ & Basal layer & Foveola of gland & Crypt base & Crypt base \\
\hline No of stem cells & $25 \%$ of basal cells & 10 cells in gland & 4 cells in base & 1 cell in base \\
\hline $\begin{array}{l}\text { Differentiated } \\
\text { phenotypes }\end{array}$ & $\begin{array}{l}\text { Membrane lectins for } \\
\text { protection }\end{array}$ & Neutral mucin & $\begin{array}{l}\text { Brush border enzymes in } \\
\text { villi }\end{array}$ & Muc-1 mucin \\
\hline Function & Protection & $\begin{array}{l}\text { Acidification digestion, } \\
\text { protection }\end{array}$ & Digestion and absorption & $\begin{array}{l}\text { Water absorption, } \\
\text { defence, fermentation }\end{array}$ \\
\hline
\end{tabular}

TABLE II Physiologically active growth regulatory agents

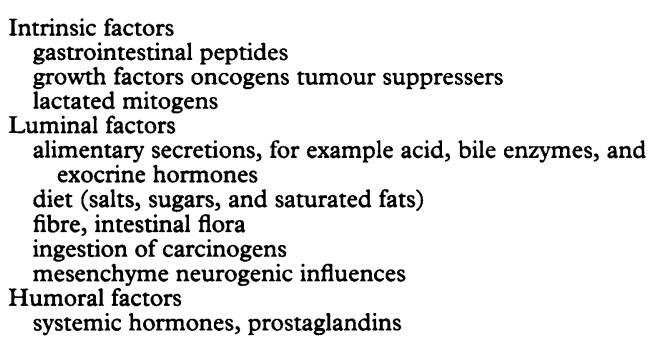

\section{SMALL INTESTINE}

It has been estimated that there are about 4-40 stem cells in the base of the crypt of Lieberkuhn in the adult (and possibly only 1 stem cell in early life) believed to occupy positions $4-5$ in the base of the intestinal crypt. ${ }^{45}$ Furthermore, the population of stem cells in a particular gland may be tightly controlled and if their number exceeds a 'predetermined quota for that epithelia' glands may undergo stochastic crypt fission (new gland formation). Radiobiological experiments on chimaeric animals suggest that high doses of radiation result in clonogenic regeneration of crypts and in some cases adjacent crypts, from the basal surviving compartment. In addition after irradiation the surviving proliferative cells phagocytose the adjacent dead cells. Cells containing 'phagosomes' (intracellular organelles containing phagocytic vacuoles) are found within 36 hours of injury in all cell lineages, showing the common origin of all the intestinal cell types.

The daughter cells of the clonogenic stem cells, with the exception of the Paneth cells, migrate up the crypt and laterally hence onto the villus.

The crypt cell production rate is roughly constant throughout the length of the intestine despite an increased crypt depth/villus height ratio in proximal small intestine because more crypts give rise to one villus in the proximal compared with the distal small intestine (duodenal crypt villus ratio 7:1, ileal crypt villus ratio $4: 1){ }^{2} 4$

The differentiated small intestinal cells are mainly confined to the top third of the superficial compartment (villi). These cells secrete many brush border enzymes, which can be further enhanced by epidermal growth factor in vivo. In addition transforming growth factor $\alpha$ expression is maximal in the superficial compartment. In this regard, reports suggest that these growth factors act by way of their common receptor, epidermal growth factor receptor, either on the basolateral or apical surfaces of intestinal cells. The role of specialised intestinal cells has yet to be fully elucidated and endocrine cells, which secrete many growth regulatory molecules and the goblet cells, which secrete novel peptides (including a large new family of molecules called trefoil peptides) are being intensively studied. 6

\section{LARGE INTESTINE}

The base of the wide tubular crypts in the colonic mucosa may contain a single functional stem cell, with few potential stem cells ${ }^{1}$ as shown by radiobiological split dose experiments. ${ }^{1}$ As in the small intestine crypt duplication may occur by bifurcations, from the apex of the gland to the superficial compartments (crypt fission). Eccentric bifurcations (glandular buds) along the length of a gland may occur also in normal and diseased mucosa. It is possible that these represent aborted crypt development resulting from the death of the stem cell generating the bud.

\section{Growth regulation/adaptation}

The molecules that act to maintain mucosal architecture and function, originate from a variety of sites and hence have different routes of action. In this context molecules may be subdivided according to their site of origin and transport; intrinsic to the mucosa (growth factors), humoral supply (hormones), and luminal origin (dietary nutrients and carcinogens) ${ }^{78}$ (Table II).

Regulatory molecules intrinsic to the mucosa include gastrointestinal peptides and gastrin. Of the many gastrointestinal peptides some have specific trophic actions on the intestinal mucosa. Gastrin stimulates gastric acid secretion and possibly also intestinal growth because the DNA, RNA, and protein content of the epithelium increases. Gastrin has been reported to increase proliferation back to normal values in the 'atrophied' proximal colon and gastric body (but not antral) mucosa. Enteroglucagon may have similar actions in the small intestine although the evidence is, in part, circumstantial. ${ }^{9}$

Systemic hormones (for example, growth hormone and thyroxine) have been reported to increase small intestinal weight and may achieve this by modest mitogenic actions.

Prostaglandins are endogenous molecules (long lived analogues have now been pharmaceutically produced) and these molecules may be of benefit in the prophylaxis against nonsteroidal anti-inflamatory drug induced intestinal ulcers. In this regard large differences in proliferation are seen between human biopsy 
specimens taken from the edge of an ulcer and from an unaffected region of the mucosa. Nonsteriodal anti-inflammatory drugs seem to inhibit regeneration by abolishing this proliferative difference. Prostaglandins may protect the mucosa from this inhibitory effect when given prophylactically. ${ }^{10-12}$ Available data suggest, however, that prostaglandins act by complex mechanisms and may entail a favourable modulation of cell proliferation, membrane permeability, and cell migration. ${ }^{13}$

Proliferation effects induced by prostaglandins are also seen in the small bowel, but are far less noticeable in the colon.

Alimentary secretions such as gastric acid and bile acids produce dose related increased mitogenic responses in the oesophagus, stomach, and small intestine and carcinogenic responses in the colon.

Growth factors may produce more complex patterns of epithelial adaptation compared with other growth regulatory molecules. In this context their actions seem to be tissue, dose, and disease specific because they can modulate proliferation, differentiation, and expression of other novel peptide molecules. ${ }^{2} 6$

Transforming growth factor $\alpha$ peptide and its mRNA are expressed throughout the length of the intestinal mucosa on the tips of the villi. Epidermal growth factor on the other hand is normally present only in small amounts on the superficial surface of colonic epithelium. The physiological significance of these growth factors in humans is not yet known, in part, because the precise localisation of their receptor in the crypts and on the superficial enterocyte cell membranes has still to be elucidated (apical or basolateral). ${ }^{6}$ It may also be of some significance that epidermal growth factor is also a lactated mitogen, which can modulate normal alimentary development in the breast fed infant. ${ }^{14}$

Recently the discovery of novel peptides with a clover leaf structure (trefoil peptides) have been reported to have growth regulatory properties. They have some structural homology with the epidermal growth factor/transforming growth factor $\alpha$, insulin like growth factor family, suggesting, in part, a common growth regulatory function. Two peptides, in particular, human spasmolytic polypeptide (hSP) and an oestrogen inducible breast cancer associated peptide (pS2) have been identified in specific morphological compartments in the alimentary tract. Expression of $\mathrm{hSP}$ alone is seen in Brunner's glands in the duodenum but has mitogenic actions on colorectal cells. pS2 is not commonly identified in the normal intestinal mucosa, although some positive cells are seen in areas with strong expression for transforming growth factor $\alpha$. Furthermore pS2 mRNA and protein expression is upregulated in regions of the alimentary mucosa receiving mucosal damage (Table III).

Oncogenes and tumour suppressors have also gained much attention recently because they are integral to both normal cell division and also neoplastic potential.

Furthermore a recent report has suggested that oncogene expression may be induced in the
TABLE III Growth factor and trefoil peptide expression in the alimentary tract

\begin{tabular}{|c|c|c|c|c|}
\hline \multirow[b]{2}{*}{ Epithelial mucosa } & \multicolumn{4}{|c|}{ Peptides } \\
\hline & $E G F$ & $T G F \alpha$ & $p S 2$ & $h S P$ \\
\hline \multicolumn{5}{|l|}{ Oesophagus } \\
\hline normal oesophagus & - & + & - & - \\
\hline $\begin{array}{l}\text { Barrett's metaplasia } \\
\text { adenocarcinomas }\end{array}$ & $\begin{array}{l}+ \\
++\end{array}$ & $\begin{array}{l}++/+++ \\
++\end{array}$ & $\begin{array}{l}++ \\
++\end{array}$ & $\begin{array}{l}-1+ \\
++\end{array}$ \\
\hline \multicolumn{5}{|c|}{ Stomach } \\
\hline $\begin{array}{l}\text { normal mucosa } \\
\text { metaplasia } \\
\text { adenocarcinomas }\end{array}$ & $\begin{array}{l}-1+ \\
+ \\
++\end{array}$ & $\begin{array}{l}++ \\
++/+++ \\
+++\end{array}$ & $\begin{array}{l}+ \\
++ \\
++1+++\end{array}$ & $\begin{array}{l}+ \\
++ \\
++\end{array}$ \\
\hline \multicolumn{5}{|l|}{ Small intestine } \\
\hline normal & - & ++ & - & + \\
\hline \multicolumn{5}{|l|}{ Colon } \\
\hline normal & - & ++ & $-1+$ & $-1+$ \\
\hline hyperplastic polyps & $+/++$ & $-1+$ & +++ & - \\
\hline adenocarcinomas & + & $-1+$ & + & + \\
\hline
\end{tabular}

Peptide expression:-absent, + expressed weakly, ++ expressed moderately, +++ expressed maximally.

$\mathrm{EGF}=$ epidermal growth factor, TGF $\alpha=$ transforming growth factor $\alpha, \mathrm{pS} 2=$ oestrogen inducible breast cancer associated peptide, $\mathrm{hSP}=$ human spasmolytic polypeptide, $\mathrm{UACL}=$ ulcer associated cell lineage.

small bowel by certain dietary regimens. In the large bowel many oncogens and oncosuppressors have been reported, c-ras, OCC, and $\mathrm{p} 53$ have been most implicated in the serial progression of dysplasia-neoplastic sequence. ${ }^{14}$

Dietary components (amines, saturated fats, and ingested carcinogens) have been reported to stimulate growth independent of their nutritional value. In this context sodium chloride and glucose (salts and sugars) usually produce proliferative responses in line with nutritional demand, however, other salts such as magnesium chloride may produce colonic hypertrophy. Dimethylamine, amino-methylphenylimidazopyridine (phIP), and saturated fats exert proliferative responses and are also associated with the induction of premalignant lesions in distal colonic sites. ${ }^{15} 16$

The production of short chain fatty acids by the colonic luminal microflora may have the most potent mitogenic effects. These include acetate, butyrate, and propionate of which butyrate is preferentially metabolised as a substrate of oxidative metabolism by colonocytes. ${ }^{17}$ In addition other trophic factors are increased in response to fibre ingestion such as mucosal expression of epidermal growth factor. ${ }^{18}$

Furthermore, the epithelial tissue beneath the mucosa, the mesenchyme, not only provides structural support and nutrition but is also reported to be important in the normal development of intestinal mucosa, in part, by regulating the ratio of mucosal proliferation and differentiation. Finally, neurogenic influences are also important in the normal development of intestinal mucosa as denervation of mucosa may lead to mucosal atrophy.

\section{Disease adaptation}

In general terms abnormal conditions of the small intestine result in failure of digestive processes (for example, lipid malabsorption caused by Crohn's disease, salt and water imbalances may stem from acute changes in colonic mucosal permeability caused by xenobiotics such as cholera toxin). Abnormal conditions of the colon (colonic adenomas), 
however, may be the result of failure of cancer surveillance and defence. In both these cases increased mucosal proliferation may be associated with changed expression of growth factors. Increased expression of transforming growth factor $\alpha$ is associated with more severe mucosal inflammation in Crohn's disease especially in the ulcer associated cell lineage, while increasing dysplastic change in tubulovillous polyps is associated with decreased transforming growth factor $\alpha$ expression. These apparently paradoxical results are due, in part, to the dual actions of growth factors, which can induce differentiation or stimulate proliferation, or both according to dose, tissue sensitivity, and presence of disease.

In conclusion, the alimentary tract has several functions in addition to digestion of food and preventing the transfer of many molecular or biological agents that can, and do, prove harmful to host.

The gastrointestinal mucosa exhibits regional differences in morphology from proximal small intestine to distal colon (proximal distal gradient). In addition as cells migrate luminally they mature and express proteins primarily associated directly or indirectly with specific absorptive functions (vertical epithelial gradient).

The regulation of this mucosal structure requires a complex cascade of 'growth regulatory' molecules, which exert local and distant effects by autocrine, endocrine, paracine, exocrine routes.

There is some evidence that this heirachy of control may experience adaptive changes during aging in humans resulting in increased mucosal proliferation (chronological gradient). Furthermore, growth control mechanisms may also become mutated or induced as a result of environmental influences. Such aberrations increase the expression of positive regulatory molecules and decrease expression of growth inhibitory molecules (pathological gradients).
1 Willett $W$. The search for the causes of breast and colon cancer. Nature (Lond) 1989; 338: 389-93.

2 Wright NA, Alison MR. The biology of epithelial cell populations. Vol 2. Oxford: Clarendon Press, 1987.

3 Jankowski J, Wright NA. Epithelial stem cells in gastrointestinal morphogenesis, adaption and carcinogenesis. Semin Cell Biol 1992; 3: 445-56.

4 Potten CS, Loeffler M. Stem cells: attributes, cycles, spirals, pitfalls and uncertainties. Lessons for and from the crypt. Development 1990; 110: 1001-20.

5 Loeffler M, Stein R, Wichman HE, Potten CS, Kaur P, Chwalinski S. Intestinal cell proliferation I. A comprehensive model of steady-state proliferation in the crypt. Cell Tissue Kinet 1986; 19: 627-45.

6 Jankowski J, Wright NA. Gene expression in the alimentary tract; modulation of epithelial proliferation, differentiation and peptide transcription by growth regulatory peptides. Current Medical Literature-Gastroenterology 1992; 11: 78-85.

7 Goodlad RA, Wright NA. Changes in intestinal cell proliferation, absorptive capacity and structure in young, adult and old rats. $\mathcal{F}$ Anat 1990; 173: 109-18.

8 Goodlad RA, Wilson TG, Lenton W, Wright NA, Gregory $\mathrm{H}$, McCullagh KG. Intravenous but not intragastric urogastrone-EGF is trophic to the intestinal epithelium of parentarally fed rats. Gut 1987; 28: 573-82.

9 Goodlad RA, Ratcliffe B, Fordham JP, Ghatei MA, Domin J, Bloom SR, et al. Plasma enteroglucagon, gastrin and peptide YY unconventional and germ-free rats refed with a fibre-free of fibre-supplemented diet. $Q \mathcal{F}$ Exp Physiol 1989; 74: 437-42.

10 Goodlad RA, Lee CY, Levin S, Wright NA. Effects of the prostaglandin analogue misoprostol on cell proliferation in the canine small intestine. Exp Physiol 1991; 76: 561-6.

11 Levi S, Goodlad RA, Lee CY, Stamp G, Walport MJ, Wright NA, et al. Inhibitory effect on non-steriodal antiinflammatory drugs on mucosal cell proliferation inflammatory drugs on mucosal cell proliferation associat

12 Levi S, Goodlad RA, Stamp G, Lee CY, Walport MJ, Wright NA, et al. Effects of non-steriodal anti-imflammatory drugs and misoprostal on gastric and duodenal epithelial proliferation in patients with arthritis. Gastroenterology 1992; 102: 1605-11.

13 Dembinski A, Konturek SJ. Effects of E, F, and I series prostaglandins and analogues on growth of gastrointestinal mucosa and pancreas. Am f Physiol 1985; 248: 170-5.

14 Fearon ER, Vogelstein B. Agenetic model for colorectal tumorigenesis. Cell 1990; 61: 759-67.

15 Scheppach W, Sommer H, Kirchner T. Effect of butyrate enemas on the colonic mucosa in distal ulcerative colitis. Gastroenterology 1992; 103: 51-6.

16 Chinery R, Goodlad RA, Wright NA. Soy polysaccharide in an enteral diet: effects on rat intestinal cell proliferation, morphology and metabolic function. Clin Nutr 1992; 11: 277-83.

17 Goodlad RA, Ratcliffe BR, Fordham JP, Wright NA. Does dietary fibre stimulate intestinal epithelial cell proliferation in germ-free rats? Gut 1989; 30: 820-5.

18 Goodlad RA, Raja KB, Peters TK, Wright NA. The effects of urogastrone-EGF on small intestinal brush border enzymes and mitotic activity. Gut 1991; 32: 410-1. 